\title{
Augmentation of Extraction Sockets - A Requisite for Future Rehabilitation
}

\author{
Savina gupta ${ }^{1 *}$, Sanchaynee Pathak ${ }^{2}$, Abhinav Neog ${ }^{3}$, Hirkani Attarde ${ }^{4}$ and Jai Narula ${ }^{5}$ \\ ${ }^{1}$ MDS (Oral \& Maxillofacial Surgery), Professor \& HOD Jaipur Dental College, Jaipur, Rajasthan, India \\ ${ }^{2}$ Post Graduate Student, Department of Oral and Maxillofacial Surgery, Jaipur Dental College, Jaipur, Rajasthan, India \\ ${ }^{3}$ Post Graduate Student, Department of Oral and Maxillofacial Surgery, Jaipur Dental College, Jaipur, Rajasthan, India \\ ${ }^{4}$ Associate Professor, Department of Oral and Maxillofacial Surgery, YMT Dental College \& Hospital, Kharghar, Navi Mumbai, Maharashtra, India \\ 5 Jai Narula, Student of International Dental Program, Moldova State University of Medicine and Pharmacy, Moldova, India
}

${ }^{*}$ Corresponding Author: Savina Gupta, Department of Oral \& Maxillofacial Surgery, Jaipur Dental College, Maharaj Vinayak Global University, NH 11C, Dhand, Tehsil Amer, Jaipur-302028, Rajasthan, India; Phone No: +919833925340; +919079216226; E-Mail: drsavinagupta@hotmail.com

Received: January 10, 2020; Accepted: January 20, 2020; Published: January 30, 2020

\begin{abstract}
Purpose: In this prospective study, bone formation in human extraction sockets is augmented with bovine- cancellous bone (Bio-Oss) and compared to bone formation in unaugmented extraction sockets.

Methods: Twenty patients with bilateral extraction sockets were included in this study. After all 40 extractions, one socket was augmented using cancellous bovine bone and another socket left to heal naturally. Bone density was measured by means of histogram, after 1 week, 1 month \& 3 months following extractions.
\end{abstract}

Results: Extraction sites with graft by the means of histogram showed significant difference in the bone density. They were significantly augmented as compared to the sockets without graft.

Conclusion: The results of the present study suggests that the use of bone xenograft as graft material for alveolar ridge preservation after extraction. This aids in future rehabilitation with implant placement or fixed prosthesis.

Keywords: alveolar bone augmentation, extraction socket, socket preservation, bone density

\section{Introduction}

Tooth extraction is one of widely the performed procedures in dentistry and it has been historically well documented that this procedure may induce significant dimensional changes of alveolar ridge. The dilemma that clinician face today is how to manage tooth extraction to provide a good ridge for the future placement of a dental implant or to maximize ridge dimension for the fabrication of fixed or removal prosthesis. If performed inadequately the resulting deformity can be considerable obstacle to the aesthetic, phonetic, and functional results; that both our patients and we clinician expect at this current time [1].

Bone resorption occurs in the first three months following extraction. The condition appears to be progressive and irreversible, resulting in a host of prosthodontics, aesthetic, and functional problems. Post extraction bone loss is accelerated in the first 6 month, followed by a gradual modelling and remodelling of the remaining bone, with as much as $40 \%$ of the alveolar height and $60 \%$ of alveolar width lost in the first 6 months [2].

Jaw deformities from tooth removal can be prevented and repaired by a procedure called socket preservation. The procedure begins with atraumatic tooth extraction. Every attempt is made to preserve the surrounding bone and soft tissue, with an example on being careful not to fracture delicate buccal plate. After the extraction, a bone graft material is placed into the socket and covered with a resorbable or non-resorbable membrane and sutured. Most importantly, socket preservation helps to maintain the alveolar architecture and significantly reduces the loss of ridge width and height following tooth removal [3].

Various materials are used in modern dental and maxillofacial surgery for bone tissue substitution and reconstruction. All osteoplastic materials can be divided into four groups by origin: autogenic, allogeneic, xenogeneic, and synthetic.

Increasing the height and width of bone helps ensure the success and longevity of dental implants. Surgeons can utilize a variety of surgical procedure in ridge augmentation. The surgical procedure will depend on amount of available bone, the amount of augmentation necessary and patient related factors.

In this prospective clinical study, after multiple extractions, one socket is filled with xenograft graft and other socket left to heal naturally and then evaluated by means of bone density test, postoperatively. 


\section{Materials and Methods}

After procuring the ethical approval from the ethical committee, 20 patients who reported to the Department of Oral and Maxillofacial Surgery, who required extractions of bilateral teeth either from maxilla or mandible. Out of these 40 extractions; all left sided sockets were preserved with bovine-cancellous bone (Bio-Oss) and were grouped as Group A; and all right sided extractions were left to heal naturally and were grouped as Group B.

To keep the study unbiased in regards of surgical expertise, only one surgeon performed all the cases in the present study.

The study protocol was explained to the patient in detail and their consent was obtained.

\section{Inclusion Criteria: -}

- Systemically healthy patients.

- Patients requiring bilateral extractions.

- Tooth which were un-restorable by endodontic treatment and free from acute infections.

- Patients who required intra-alveolar extractions.

- Patients within 18-55 years of age group.

- Patients who are willing to sign the informed consent.

\section{Exclusion Criteria:-}

- Pregnancy or lactation

- Systemically ill patients.

- Chronic generalised/localized aggressive periodontitis patients or patients having severe bone loss more than $80 \%$.

- Bone disease or the use of medications that interfered with bone metabolism

\section{Materials}

1. Deproteinized cancellous bovine bone supplied by Geistlich biomaterial, Inc. It has a granules size of $0.25 \mathrm{~mm}-1 \mathrm{~mm}$. It is marketed in a sterile airtight pack, sterilized by gamma irradiation (Geistlich Bio-Oss).

2. Vicryl suture material.

\section{Methodology}

The surgical procedure was carried out in an operating room under strict aseptic conditions. The surgeries were performed under local anaesthesia (lignocaine $2 \%$ with epinephrine 1:80,000). Furthermore, patients were given an antibiotic prophylaxis a day before surgery. The surgical procedure was performed with standard instruments set used for minor oral surgical procedures.

Multiple tooth extraction was done carefully \& atraumatically, while preserving the alveolar bone plates around the teeth. The socket was then gently flushed with normal saline.

In all left sockets, bone graft was placed. Sutures were used to approximate the grafted sockets and in all right sided ungrafted sockets were compressed digitally and allowed to heal naturally.
All patients were given postoperative instructions following extractions. Antibiotics and Analgesics were prescribed postoperatively.

Assessment of patients was done at the end of $1^{\text {st }}$ week, 1 st and $3^{\text {rd }}$ months postoperatively, based on the following parameters:

- Pain Visual Analogue Scale (VAS) (Figure 1)

- Infection - present/absent

- Inflammation - present/absent

- Swelling - present/absent

- Graft - accepted/rejected

- Bone density by means of histogram. Changes in alveolar bone level were measured by means of histogram (adobe photoshop) pixels ranging between 15000-16000.

\section{Results}

20 patients (10 males and 10 females) with mean age of 25 participated in this prospective study. Regarding the parameters of pain, swelling, infection \& inflammation in both the groups there was no significant difference. Table I represents those cases who reported with such complications. Thus, we did not procure a graphical representation of it.

For the grafts assessment in group A, clinical observation shows that all 20 patients indicated quicker healing with graft acceptance without any Necrosis (Figure 2).

On every follow up, bone density in both the groups were calculated with the help of histogram (Figure 3).

The histogram displayed on overlay plot of different stages with increase or decrease of bone density at different times, for both the groups (Figure IV). The mean range of bone densities in group A on completion of $1^{\text {st }}$ week it was $80.41 \pm 16.13$ after 1 month it was $109.52 \pm 22.25$ \& after 3 months it was $124.84 \pm 23.17$. In group B the mean range on $1^{\text {st }}$ week it was $71.67 \pm 15.17$ after 1 month $81.24 \pm 16.26$ $\&$ after 3 months it was $89.21 \pm 15.34$ (Table 2). The bone density presented in table 2 shows higher density in group $\mathrm{A}$ at the end of 3 months followed by 1 month.

The ANOVA revealed significant interaction of grafting and time $(\mathrm{P}<.001)$ (Table 3 \& Figure 5).

\section{Discussion}

In order to preserve the gift of nature, man is presently trying to be positively constructive and conservative, and thus from forest to fuel, all form of energy is being judiciously utilized [4]. The survival rate of human life has itself increased and hence maxillofacial structures, including natural teeth, are being preserved in an attempt toward this goal [5]. It is crucial to preserve the dimensions of the alveolar ridge after tooth extraction to achieve a predictable aesthetic and functional prosthetic restoration.

Alveolar preservation or Reconstruction is necessary for support, esthetics and function of any prosthodontic rehabilitation. M. M. Devan suggested that preservation of the alveolar ridge was an easier task than to reconstruct it, once it was lost [6]. 


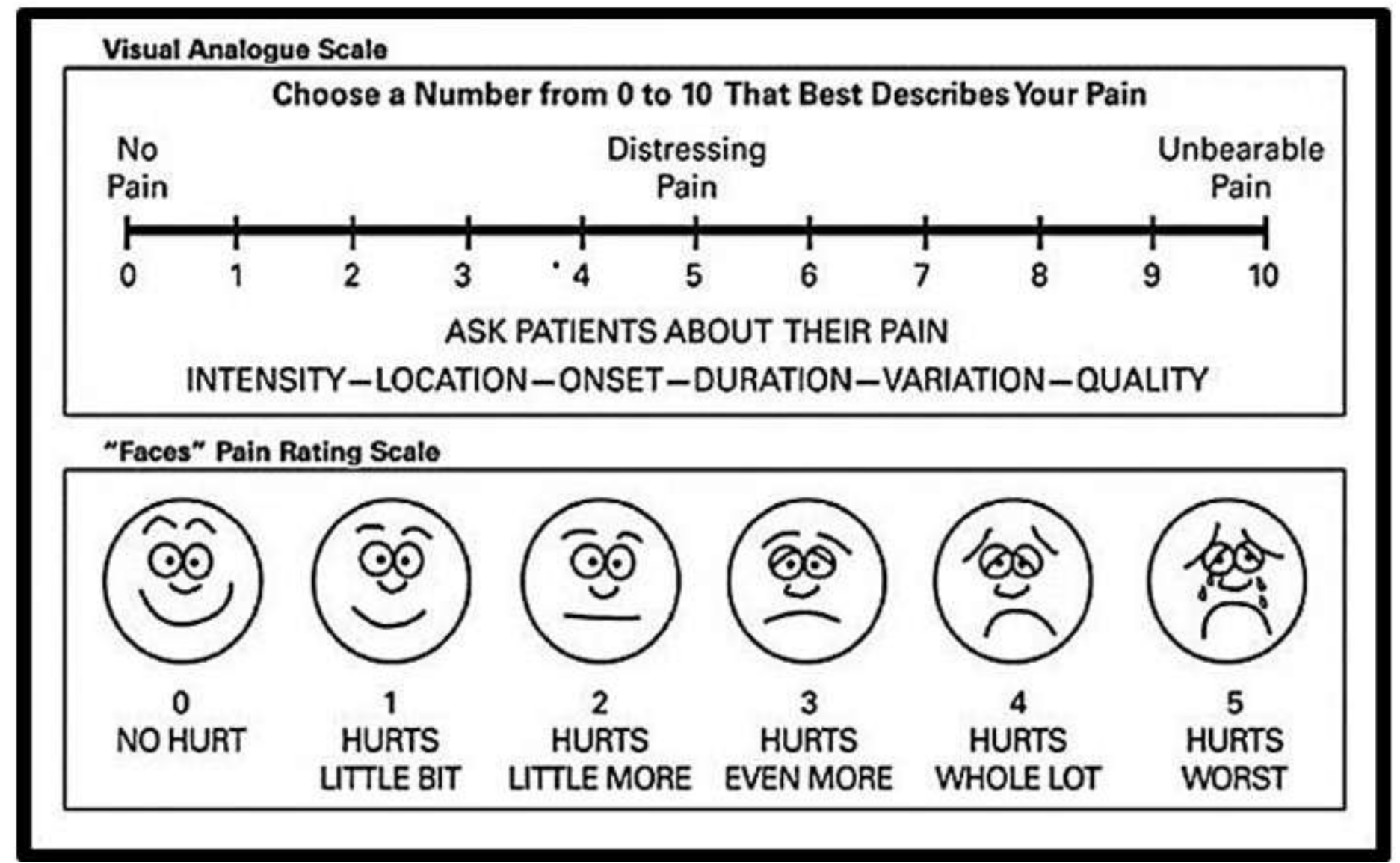

Figure 1. Visual Analogue Scale (VAS).
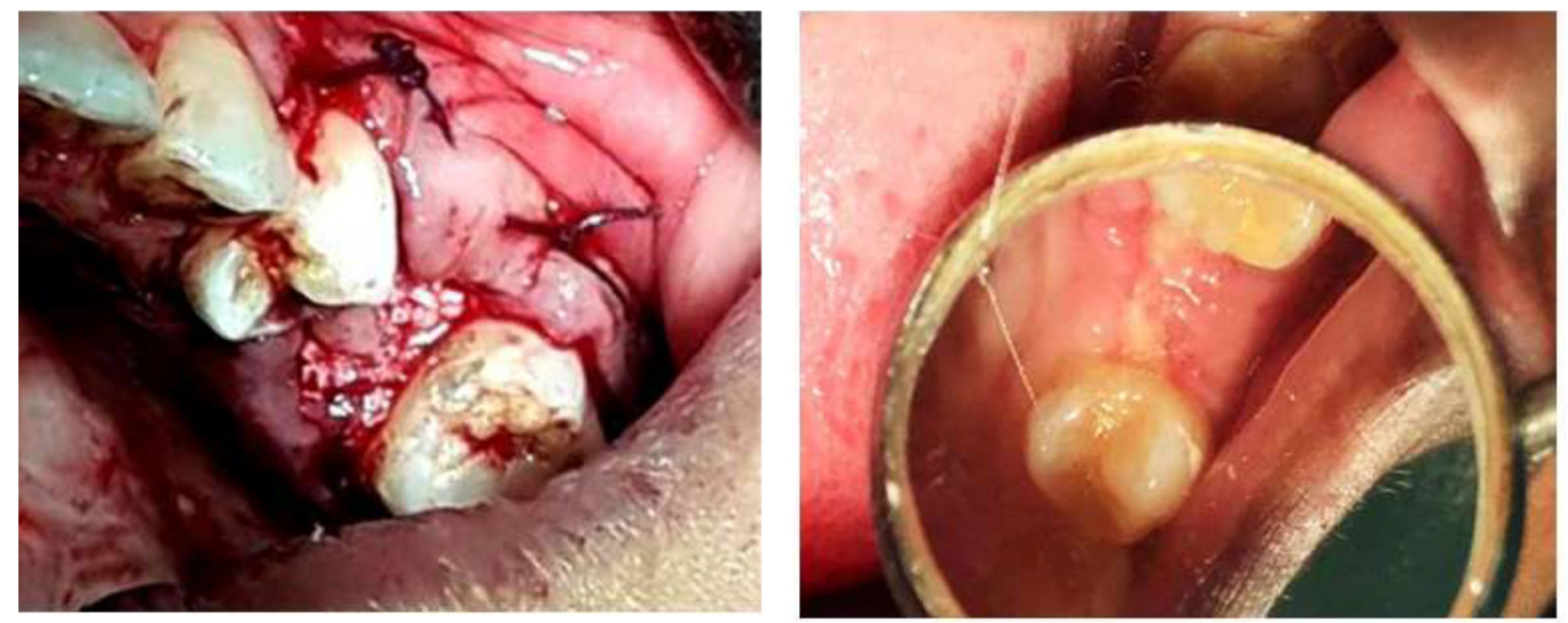

Figure 2. Placement of Bio Oss ${ }^{\circledR}$ Bone Graft \& Post-operative healing of the socket. 


\section{WITH GRAFT WITHOUT GRAFT \\ Pre-Operative}
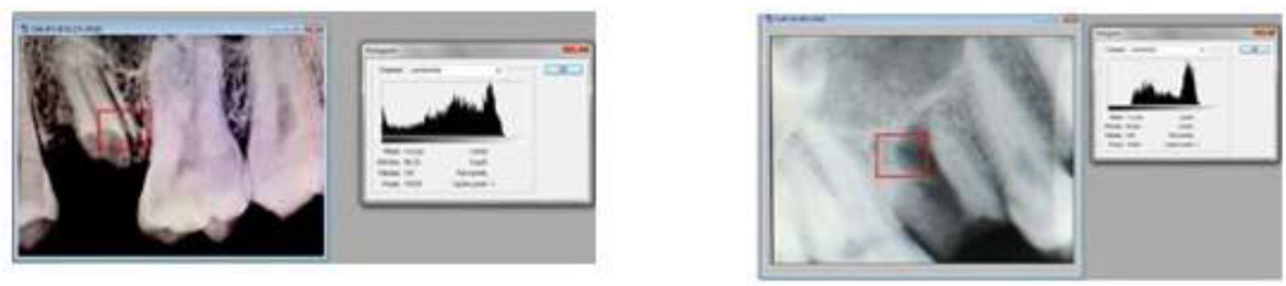

\section{$1^{\text {st }}$ week Post-Operative}
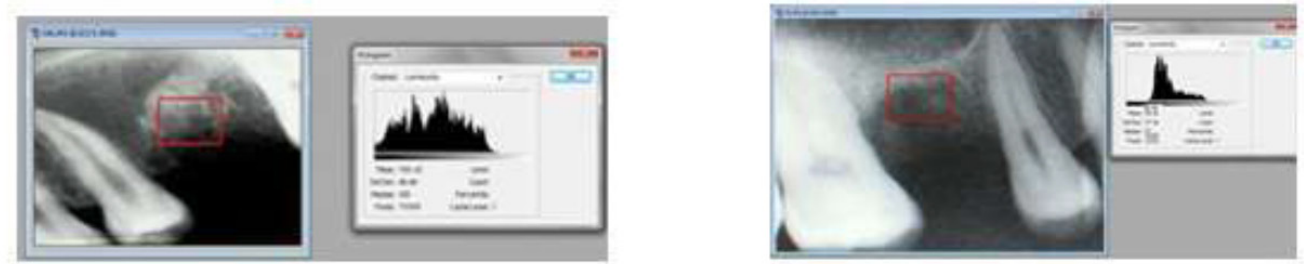

\section{$1^{\text {st }}$ month Post-Operative}
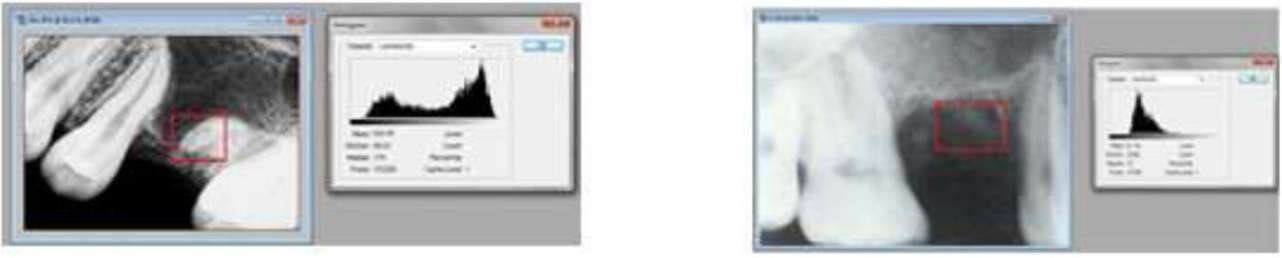

$3^{\text {rd }}$ month Post-Operative
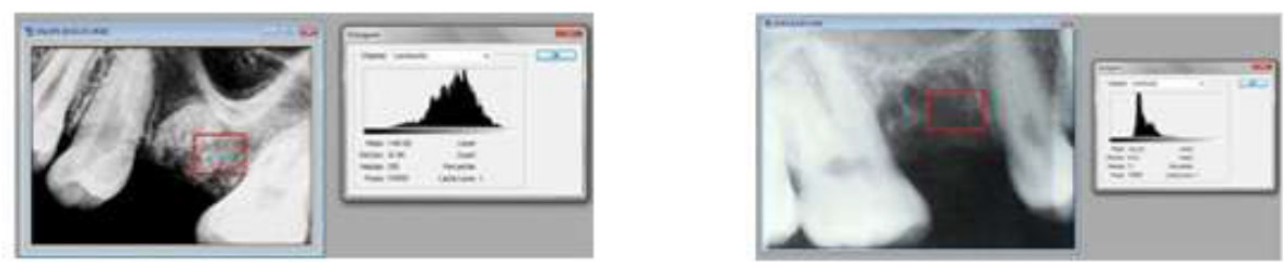

Figure 3. Mean Bone Density Measurement by Abode Photoshop ${ }^{\circledR}$ Histogram.

Range: 15000 To 16000 Pixels. 

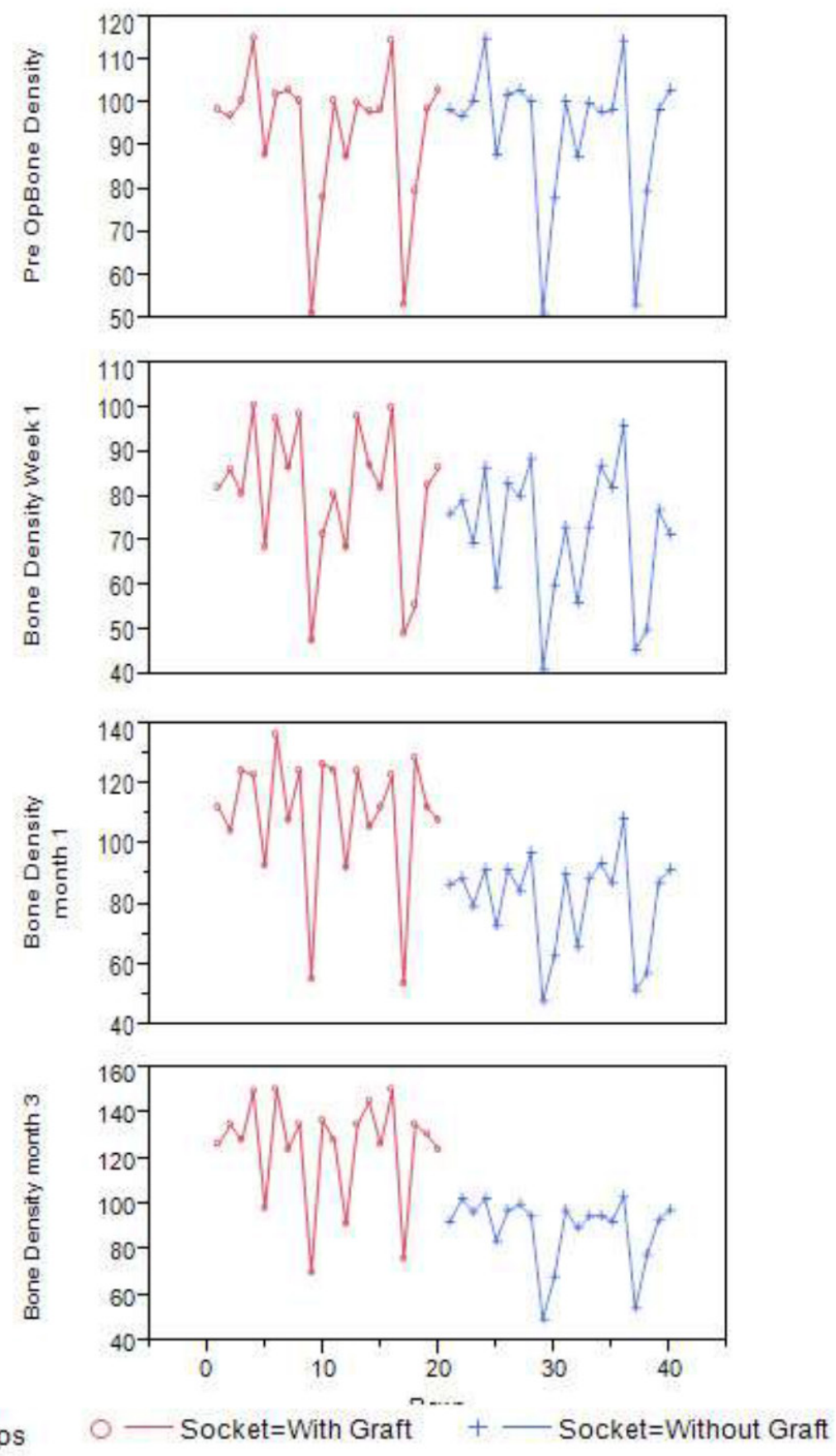

Figure 4. Overlay Plot showing increase or decrease of bone density at different interval of times for both the groups.

The idea of directing host bone into a particular defect is not a new one [7]. The principle of sealing off an anatomical site for improved healing of a certain tissue type and directing regeneration by some type of mechanical barrier or by various resorbable bone grafts has been used in experimental osseous facial reconstruction since the mid-1950s [7].

Alveolar ridge resorption following tooth removal is physiologically undesirable and possibly unavoidable phenomenon. Significant knowledge exists of the healing process of extraction wounds, including contour changes caused by bone resorption and the cascade of histologic events in both animals and humans. It is common to see approximately $50 \%$ of the alveolar width and height resorbed within the first three months [8-10]. This can lead to ridge deformation and many other complications.

The use of bovine cancellous xenograft for bone regeneration has enhanced the surgeon's ability to reconstruct deficient alveolus. Graft used in our study, is deproteinized cancellous (spongiosa) bovine bone supplied by Geistlich biomaterial, Inc. The graft particles are incorporated over time within living bone which provides long-term volume preservation [11-14]. The bio functionality of this graft is characterized by its topographic structure, hydrophilic properties and the biologic interaction that supports reliable bone formation [15]. 


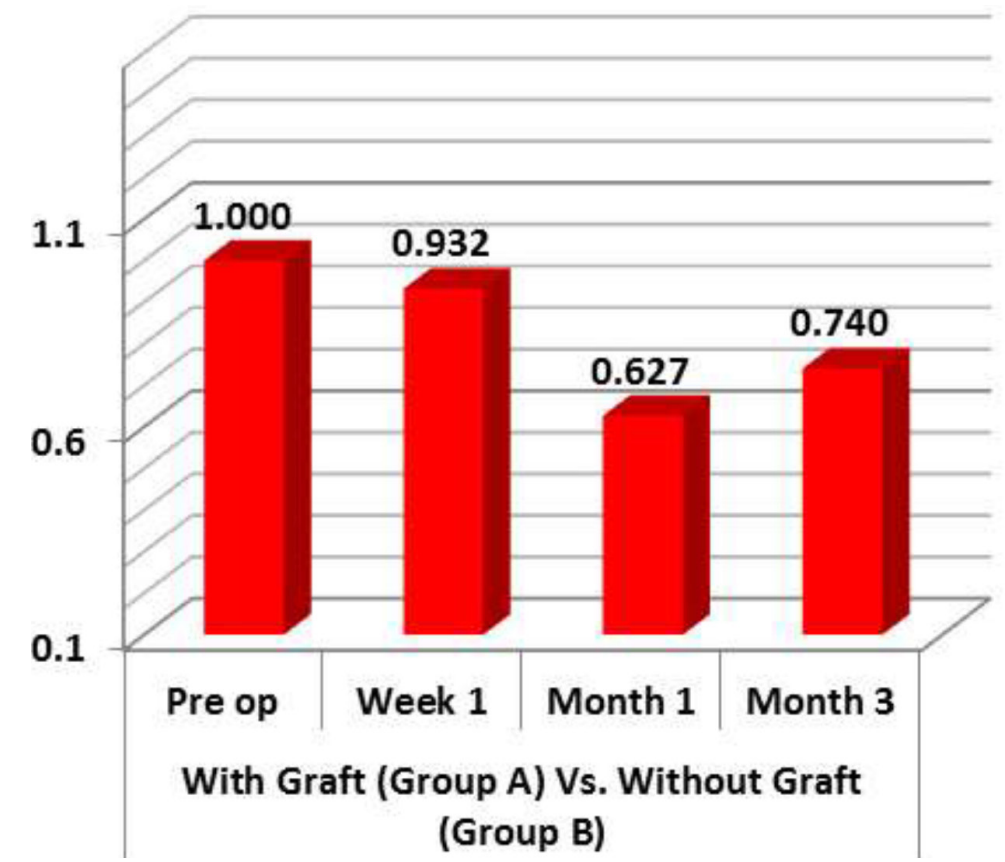

Bone density Co-relation

Figure 5. Bone density correlation.

Table 1. Prospective observations of parameters in volunteer participants Count (\%).

\begin{tabular}{|c|c|c|c|c|c|c|}
\hline \multirow[t]{2}{*}{ Graft } & \multirow[t]{2}{*}{ Parameter } & \multirow[t]{2}{*}{ Indication } & \multicolumn{4}{|c|}{ Time of Observation } \\
\hline & & & Preop & Week 1 & Month 1 & Month 3 \\
\hline \multirow{9}{*}{$\begin{array}{l}\text { Group A } \\
(\mathrm{n}=20)\end{array}$} & \multirow[t]{2}{*}{ Swelling } & Absent & $17(85 \%)$ & $20(100 \%)$ & $20(100 \%)$ & $20(100 \%)$ \\
\hline & & Present & $3(15 \%)$ & $0(0 \%)$ & $0(0 \%)$ & $0(0 \%)$ \\
\hline & \multirow[t]{2}{*}{ Pain VAS Scale } & Absent & $11(55 \%)$ & $20(100 \%)$ & $20(100 \%)$ & $20(100 \%)$ \\
\hline & & Present & $9(45 \%)$ & $0(0 \%)$ & $0(0 \%)$ & $0(0 \%)$ \\
\hline & \multirow[t]{2}{*}{ Infection } & Absent & $17(85 \%)$ & $20(100 \%)$ & $20(100 \%)$ & $20(100 \%)$ \\
\hline & & Present & $3(15 \%)$ & $0(0 \%)$ & $0(0 \%)$ & $0(0 \%)$ \\
\hline & \multirow[t]{2}{*}{ Inflammation } & Absent & $17(85 \%)$ & $20(100 \%)$ & $20(100 \%)$ & $20(100 \%)$ \\
\hline & & Present & $3(15 \%)$ & $0(0 \%)$ & $0(0 \%)$ & $0(0 \%)$ \\
\hline & Graft & & - & \multicolumn{3}{|c|}{ With Graft All were accepted } \\
\hline \multirow{8}{*}{$\begin{array}{l}\text { Group B } \\
(\mathrm{n}=20)\end{array}$} & \multirow[t]{2}{*}{ Swelling } & Absent & $15(75 \%)$ & $20(100 \%)$ & $20(100 \%)$ & $20(100 \%)$ \\
\hline & & Present & $5(25 \%)$ & $0(0 \%)$ & $0(0 \%)$ & $0(0 \%)$ \\
\hline & \multirow[t]{2}{*}{ Pain VAS Scale } & Absent & $15(75 \%)$ & $20(100 \%)$ & $20(100 \%)$ & $20(100 \%)$ \\
\hline & & Present & $5(25 \%)$ & $0(0 \%)$ & $0(0 \%)$ & $0(0 \%)$ \\
\hline & \multirow[t]{2}{*}{ Infection } & Absent & $15(75 \%)$ & $20(100 \%)$ & $20(100 \%)$ & $20(100 \%)$ \\
\hline & & Present & $5(25 \%)$ & $0(0 \%)$ & $0(0 \%)$ & $0(0 \%)$ \\
\hline & \multirow[t]{2}{*}{ Inflammation } & Absent & $15(75 \%)$ & $20(100 \%)$ & $20(100 \%)$ & $20(100 \%)$ \\
\hline & & Present & $5(25 \%)$ & $0(0 \%)$ & $0(0 \%)$ & $0(0 \%)$ \\
\hline
\end{tabular}

Table 2. Prospective Bone Density (LS Mean \pm SD).

\begin{tabular}{|l|c|c|c|c|}
\hline Effect & Pre Op & Week 1 & Month 1 & Month 3 \\
\hline Group A & $93.26 \pm 16.80^{\mathrm{BC}}$ & $80.41 \pm 16.13^{\mathrm{CD}}$ & $109.52 \pm 22.25^{\mathrm{AB}}$ & $124.84 \pm 23.17^{\mathrm{A}}$ \\
\hline Group B & $93.26 \pm 16.79^{\mathrm{BC}}$ & $71.67 \pm 15.17^{\mathrm{D}}$ & $81.24 \pm 16.26^{\mathrm{CD}}$ & $89.21 \pm 15.34^{\mathrm{C}}$ \\
\hline
\end{tabular}

Superscript indicated connecting letters by Tukey HSD. Letters not similar are significantly different, $(\mathrm{P}<.001)$. 
Table 3. Pearson Correlation of Bone Density between jaws within participants.

\begin{tabular}{|l|l|c|}
\hline \multicolumn{1}{|c|}{ Group A } & \multicolumn{1}{|c|}{ Group B } & $\begin{array}{c}\text { Bone Density } \\
\text { Correlation }\end{array}$ \\
\hline Pre Op & Pre Op & $1.000^{* *}$ \\
\hline Week 1 & Week 1 & $0.932^{* *}$ \\
\hline Month 1 & Month 1 & $0.627^{* *}$ \\
\hline Month 3 & Month 3 & $0.740^{* *}$ \\
\hline
\end{tabular}

$* *$ Significant at $\mathrm{P}(<.001)$.

In our study, the dimensions of the grafted alveolar ridge were largely preserved both horizontally and vertically after 3 months of extraction. Moreover, the bone density in the extraction socket was significantly greater 1month after extraction than in the naturally healed sockets. The slow resorption and long-term stability of xenograft appears to be an advantage for preserving alveolar ridge structures. Similar finding were demonstrated by Nevins et al showed that there is a good amount of ridge preservation after extraction of teeth in anterior region [16]. While Artzi et al observed minimal higher rates of bone in human extraction sockets filled with bovine bone mineral investigated after a healing period of 3 months than after a 6-week healing period [17].

These data demonstrates that bone resorption cannot be completely prevented even with effective socket preservation, but the dimensions of the alveolar ridge and keratinized soft tissue can be preserved to a major extent by socket preservation with Bio-Oss so that an optimal future implant site can be created predictably.

\section{Conclusion}

Alveolar ridge resorption has long been considered an unavoidable consequence of tooth extraction. With today's increasing appearance consciousness, the days of just extracting a tooth and replacing it later is unacceptable to many patients. It is vital to preserve and maintain the edentulous ridge and gingival architecture.

In our study we discovered that bone regeneration using bovine cancellous seems promising. Clinical as well as stastical analysis of our study demonstrate an advantage of grafting after extraction for future rehabilitation with implant placement or fixed prosthesis, over the ungrafted socket. More long term studies are needed to confirm the success rate of implants placed in regenerated bone.

\section{Compliance with ethical standards}

- Funding: no funding received

- Conflict of interest:

- Author 1 declares that she has no conflict of interest

- Author 2 declares that she has no conflict of interest

- Author 3 declares that he has no conflict of interest

- Author 4 declares that she has no conflict of interest

- Author 5 declares that he has no conflict of interest
- Ethical approval: All procedures performed in studies involving human participants were in accordance with the ethical standards of the institutional and/or national research committee and with the 1964 Helsinki declaration and its later amendments or comparable ethical standards

- Informed consent: "Informed consent was obtained from all individual participants included in this study".

\section{References}

1. Robert Horowitz, Danny Holtzclaw, Paul S Rosen (2012) A review on alveolar ridge preservation following tooth extraction. J Evid Dent base pract S1: 149-160. [Crossref]

2. Barry K Bartee (2001) Extraction site reconstruction for alveolar ridge preservation. Part1: Rationale and materials selection. Journal of oral Implantology 17: 187-193. [Crossref]

3. Cena Dimova (2014) Socket preservation procedure after tooth extraction. Key engineering materials Trans Tech Publication 587: 325-330.

4. Rohit Madan, Vivek Gupta, Vivek K Bains, Sudhir S Patil, G P Singh, et al. (2011) Socket preservation vis-à-vis natural healing: Literature review. Asian Journal of Oral Health \& Allied Sciences 1:195-201.

5. Chandra R, Bains R, Loomba K, Pal US, Ram H, et al. (2010) Endosseous dental implant vis-à-vis conservative management: is it dilemma? Natl j maxillofac Surg 1: 26-29.

6. M. M. Devan (2005) Basic principles in impression making. J Prosthet Dent 95: 503-508. [Crossref]

7. Tasso Irinakis (2006) Rationale for socket preservation after extraction of a single -rooted tooth when planning for future Implant placement. J Can Dent Assoc 72: 917.

8. Dietmar Weng, Vera Stock, Henning Schliephake (2011) Are socket and ridge preservation techniques at the day of tooth extraction efficient in maintaining the tissues of the alveolar ridge? Systemic review. Eur J Implantol 4: 59-66.

9. Jung RE, Philipp A, Annen BM, Signorelli L, Thoma DS, et al. (2013) Radiographic evaluation of different techniques for ridge preservation after tooth extraction: a randomized controlled clinical trial. J Clinical Periodontol 40: 90-98. [Crossref]

10. Lars Schropp, Ann Wenzel, Lambros Kostopoulos, Thorkild Karring (2003) Bone healing and soft tissue contour changes following single-tooth extraction: A clinical and radiographic 12-month prospective study. Int J Periodontics Restorative Dent 23: 313-323. [Crossref]

11. Carlo Maiorana, Mario Beretta, Giovanni Battista Grossi, Franco Santoro, Alna Scott Herford, et al. (2011) Histomorphometric evaluation of anorganic bovine bone coverage to reduce autogenous grafts resorption: Preliminary result. Int $J$ Periodontics Restorative Dent 5: 71-78. [Crossref]

12. Traini Traini, Pascal Valentini, Giovanna Lezzi, Adirano Piattelli (2007) A histologic and histomorphometric evaluation of anorganic bovine bone retrieved 9 years after a sinus augmentation procedure. $J$ Periodontol 78: 955-961. [Crossref]

13. Arne Mordenfeld, Tomas Albrektsson Mats Hallman (2014) A 10 year Clinical and radiographic study of implants placed after maxillary sinus floor augmentation with an 80:20 mixture of deprotinized bovine bone and autogenous bone. Clinical Implant Dentistry and Related Research 16: 435-436. [Crossref]

14. Galindo-Moreno P, Pedro Hernandez-cortes, Francisco Mesa, Nelson Carranza, Gintaras Juodzbalys, et al. (2012) Slow resorption of anorganic bovine bone by osteoclasts in maxillary sinus augmentation. Clinical Implant Dentistry and Related Research 15: 858-866. [Crossref]

15. Mueedul Islam, Mohammed Imran, Harikeerthy Panthala, Azhar Khan, Shoaib N Parkar, et al. (2017) Processed Bovine Dentine and Bone Xenograft (BIO OSS) For Bone Regeneration and Repair-A Comparative Animal Study. Saudi J. Oral. Dent. Res 2: 303 .

16. Myron Nevins, Marcelo Camelo, Sergio De Paoli, Bernard Friedland, Robert K Schenk, et al. (2006) A study of the fate of the buccal wall of extraction sockets of teeth with prominent roots. Int J Periodontics \& Restorative Dentistry 26: 19-29. [Crossref]

17. Zvi Artzi and Carlos E. Nemcovsky (1998) The application of deproteinized bovine bone mineral for ridge preservation prior to implantation. Clinical and histological observations in a case report. J Periodontol 69: 1062-1067. [Crossref]

Citation:

Savina Gupta, Sanchaynee Pathak, Abhinav Neog, Hirkani Attarde, Jai Narula (2020)Augmentation ofExtractionSockets-ARequisiteforFutureRehabilitation. J Dent Maxillofacial Res Volume 3(1): 1-7. 